\title{
Syrinx Disappearance Following Laminoplasty in Cervical Canal Stenosis Associated With Chiari Malformation -Case Report-
}

\author{
Naoki KATO, Toshihide TANAKA, Hiroyasu NAgASHIMA*, Takao ARAI, \\ Yuzuru HASEGAWA, Satoshi TANI*, and Toshiaki ABE* \\ Department of Neurosurgery, Jikei University School of Medicine Kashiwa Hospital, \\ Kashiwa, Chiba; \\ ${ }^{*}$ Department of Neurosurgery, Jikei University School of Medicine, Tokyo
}

\begin{abstract}
A 50-year-old woman presented with nuchal pain, clumsiness in both hands, and gait disturbance. Cervical magnetic resonance (MR) imaging showed cervical canal stenosis at C3-C7 levels associated with a syrinx and cerebellar tonsillar herniation. The patient underwent C3-C7 laminoplasty. Her symptoms improved completely, and the patient was discharged 10 days after operation. Postoperative MR imaging showed disappearance of the syrinx. This case suggests that cerebellar tonsillar herniation may not cause syringomyelia. Posterior decompression, such as laminectomy and laminoplasty, without foramen magnum decompression may be an appropriate surgical strategy for diffuse cervical canal stenosis associated with syringomyelia below the narrow canal, even in the presence of co-existing Chiari malformation.
\end{abstract}

Key words: cervical canal stenosis, syringomyelia, Chiari malformation, laminoplasty

\section{Introduction}

Syringomyelia is characterized by fluid-filled cavities extending longitudinally along the spinal cord, and is most commonly associated with extrinsic compressive lesions at the craniocervical junctions. This condition is often associated with foramen magnum or spinal pathologies that impede cerebrospinal fluid (CSF) flow, including Chiari type I malformation, arachnoiditis, basilar impression, and occipital encephalocele. ${ }^{8)}$ Other causes include spinal arachnoiditis and intramedullary spinal tumors, such as ependymoma. Traumatic cervical canal stenosis may result in secondary syrinx formation. Cervical spondylosis and canal stenosis associated with syringomyelia are rarely reported..$^{1-10)}$

Cervical canal stenosis associated with a syrinx and Chiari malformation type $I$ is extremely rare. Whether foramen magnum decompression is needed in addition to posterior decompression of the spinal cord remains unclear, although posterior decompression of spinal canal stenosis associated with syringomyelia without cerebellar tonsillar herniation may result in syrinx disappearance.

We treated a patient with cervical canal stenosis at C3-C7 levels associated with a syrinx and cerebellar tonsillar herniation by laminoplasty without foramen magnum decompression, which resulted in disappearance of the syrinx, suggesting that syringomyelia with cervical canal stenosis may be caused by the difference in the CSF pressure between the stenosis and the upper level of the syrinx, and that cerebellar tonsillar herniation may not have an effect on syrinx formation.

\section{Case Report}

A 50-year-old woman presented with nuchal pain, progressive clumsiness in both hands, and gait disturbance. Neurological examination revealed delayed finger opening, weakness of finger flexion and extension, and finger dysesthesia. The deep tendon reflexes were exaggerated in the bilateral upper and lower limbs, with no pathological reflexes. Cervical magnetic resonance (MR) imaging demonstrated severe cervical canal stenosis at the C3-C7 levels and a syrinx at the C6-T1 levels. Cerebellar tonsillar herniation was also observed (Fig. 1) The diagnosis was cervical canal stenosis associated with Chiari malformation type I. Laminoplasty was performed at the C3-C7 levels. Foramen magnum decompression was not performed. Soon after the operation, the patient's neurological symptoms improved dramatically, and her postoperative course was uneventful. The patient was discharged 10 days after the operation with no neurological deficits. Postoperative MR imaging one month after operation revealed disappearance of the syrinx (Fig. 2). 


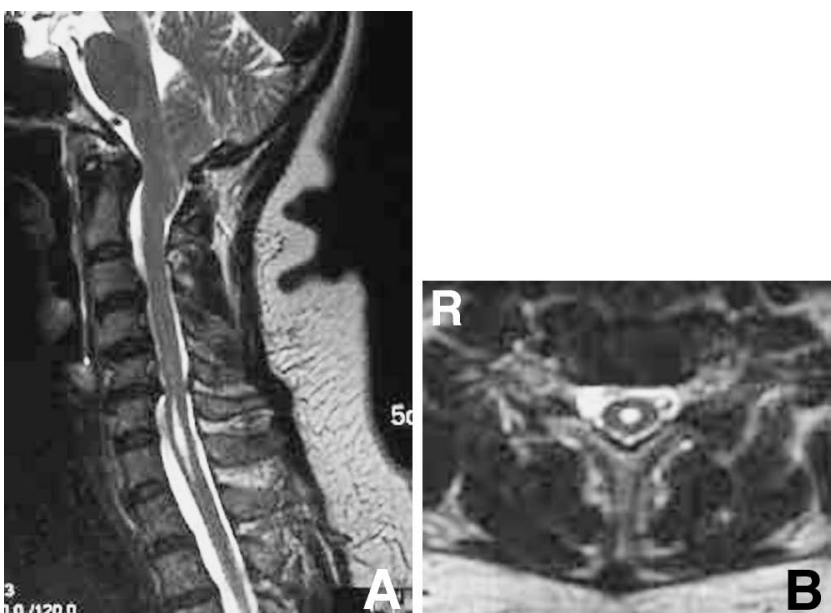

Fig. 1 Preoperative sagittal (A) and axial (B) $\mathrm{T}_{2}$-weighted magnetic resonance images demonstrating canal stenosis at $\mathrm{C4}-\mathrm{C5}$ and C5-C6 levels with cord compression and syrinx formation at C6-C7 and C7-T1 levels. Axial scan shows C5-C6 levels.
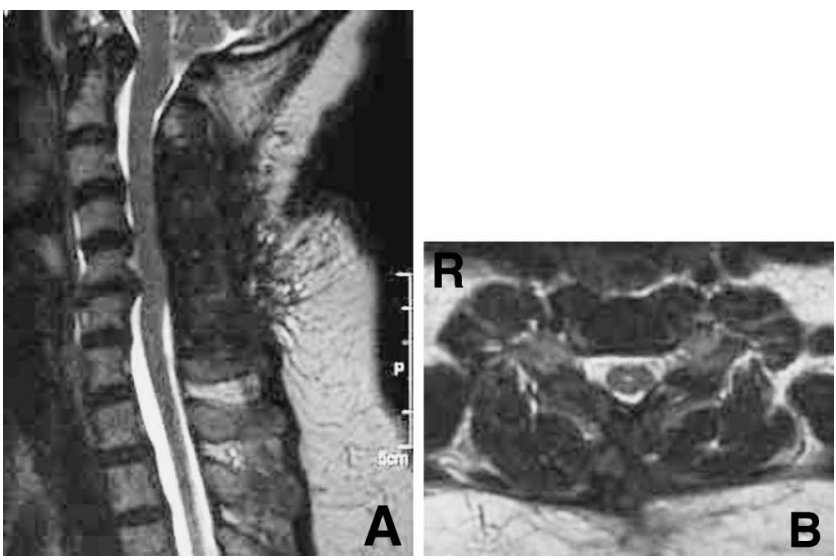

Fig. 2 Postoperative sagittal (A) and axial (B) $T_{2}$-weighted magnetic resonance images showing cervical cord decompression and resolution of the syrinx at C5-C6, C6-C7, and C7-T1 levels. Axial scan shows C5-C6 levels.

\section{Discussion}

The etiology of syringomyelia in association with cervical spondylosis is not completely understood. The most recent theory suggests that subarachnoid obstruction predisposes to the occurrence of transient increases in relative CSF pressure above the occlusion compared with below. The development of high fluid pressure and syrinx formation within the cord may counteract the local effect of the primary compressive lesion, and so may represent a protective phenomenon. The etiology may involve long-standing static and dynamic intermittent compression of the spinal cord by instability resulting in disorders of CSF dynamics in the spinal arachnoid space and pooling of an abnormal amount of CSF, supported by narrowing of the syrinx below the canal stenosis, and suggesting that the sloshing effect is related to syrinx formation. ${ }^{4)}$

In the present case, cervical canal stenosis was associated with cerebellar tonsillar herniation in contrast to a previous case. ${ }^{6)}$ Cervical canal stenosis associated with the co-existence of syringomyelia and tonsillar herniation is extremely rare. Collapse of the syrinx and improvement of related symptoms after decompressive surgery suggest that canal stenosis associated with syringomyelia has a genuine causative link, and is not a simple coincidence or related to tonsillar herniation.

The cerebellar tonsil acts as a piston on the partially closed cervical subarachnoid space, increasing the cervical arachnoid space pressure and then compressing the spinal cord externally to propagate the syrinx fluid caudally. Optimal surgical management to reduce the syrinx involves foramen magnum decompression and upper cervical laminectomy to expand the CSF pathway at the foramen magnum. In the present case, only laminoplasty was carried out, and the patient showed clinical improvement. Establishment of the optimal treatment strategies for syringomyelia associated with cervical canal stenosis requires understanding of the various causes of CSF flow interruption.

Cervical spondylotic myelopathy with syringomyelia has been treated by anterior ${ }^{4,6}$ or posterior decompression, ${ }^{1,2,5,6,9,10)}$ depending on the patient's neurological signs and the neuroradiological findings. However, foramen magnum decompression or syringo-subarachnoid shunting is usually carried out for syringomyelia induced by Chiari malformation. There is no established procedure for syringiomelia associated with cervical spondylosis. In the present case, the tonsillar herniation may have caused formation of the syrinx from the upper to the lower cervical cord, and that development of the cervical canal stenosis compressed the syrinx, so that the syrinx extended below the narrowing canal at C6-7 space. The neurological symptoms of delayed finger opening, weakness of finger flexion and extension, and finger dysesthesia were considered to be caused by the cervical canal stenosis rather than the cerebellotonsillar herniation.

Posterior decompression of the narrowed canal without foramen magnum decompression resulted in complete collapse of the syrinx and postoperative improvement of the clinical symptoms in the present patient, which suggests that cerebellar tonsillar herniation may not cause syringomyelia, and this case was considered to represent asymptomatic Chiari malformation. Posterior decompression, such as laminectomy and laminoplasty, without foramen magnum decompression may be an appropriate surgical strategy for diffuse cervical canal stenosis associated with syringomyelia below the narrow canal, even in the presence of co-existing Chiari malformation.

\section{References}

1) Butteriss DJA, Birchall D: A case of syringomyelia associated with cervical spondylosis. Br J Radiol 79: e123-e125, 2006

2) Kaar GF, N'Dow JM, Bashir SH: Cervical spondylotic my- 
elopathy with syringomyelia. Br J Neurosurg 10: 413-415, 1996

3) Kamegaya T, Ando T, Fukatsu H, Mizuno T, Takahashi A: [Syringomyelic syndrome secondary to cervical canal stenosis and cervical spondylosis]. Rinsho Shinkeigaku 33: 1179-1183, 1993 (Jpn, with Eng abstract)

4) Kimura R, Park YS, Nakase H, Sasaki T: Syringomyelia caused by cervical spondylosis. Acta Neurochir (Wien) 146: 175-178, 2004

5) Kubo M, Kawano O, Shiba K: [Syringomyelia associated with cervical spondylotic myelopathy: A case report]. Seikeigeka To Saigaigeka 56: 623-625, 2007 (Jpn, with Eng abstract)

6) Lee JH, Chung CK, Kim HJ: Decompression of the spinal subarachnoid space as a solution for syringomyelia without Chiari malformation. Spinal Cord 40: 501-506, 2002

7) Lucci B, Reverberi S, Greco G: Syringomyelia and syringomielic syndrome by cervical spondylosis. J Neurosurg Sci 25: 169-172, 1981
8) Milhorat TH, Capoceli AL Jr, Anzil AP, Kotzan RM, Milhorat RH: Pathological basis of spinal cord cavitation in syringomyelia: Analysis of 105 autopsy cases. J Neurosurg 82: 802-812, 1995

9) Porensky P, Muro K, Ganju A: Nontraumatic cervicothoracic syrinx as a cause of progressive neurologic dysfunction. $J$ Spinal Cord Med 30: 276-281, 2007

10) Rebai R, Boudawara MZ, Yahia MB, Mhiri C, Mansour HB: [Syringomyelobulbia associated with cervical spondylosis. Pathophysiology and therapeutic implications]. Neurochirurgie 48: 120-123, 2002 (Fre, with Eng abstract)

Address reprint requests to: Toshihide Tanaka, M.D., Department of Neurosurgery, Jikei University School of Medicine Kashiwa Hospital, 163-1 Kashiwa-shita, Kashiwa, Chiba 277-8567, Japan.

e-mail: ttanaka@jikei.ac.jp 